\title{
Well-being loss: a comprehensive metric for household disaster resilience
}

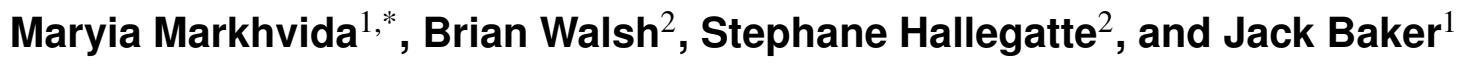 \\ ${ }^{1}$ Stanford University, Civil and Environmental Engineering, Stanford, U.S.A. \\ ${ }^{2}$ World Bank, GFDRR, Washington D.C., U.S.A. \\ *corresponding author: markhvid@stanford.edu
}

\begin{abstract}
Natural disaster risk assessments typically consider environmental hazard and physical damage, neglecting to quantify how asset losses affect households' well-being. However, for a given asset loss, a wealthy household might easily recover, while a poor household might suffer from major, long-lasting impacts. Ignoring such differential impacts can lead to inequitable interventions and exacerbate the impact of disasters on vulnerable populations. This research proposes a methodology for assessing socioeconomic effects of disasters that integrates the three pillars of sustainability: (1) environmental, i.e. environmental hazard and asset damage modeling; (2) economic, i.e. macro-economic modeling to quantify changes in sectors' production and employment; and (3) social, i.e. micro-simulations of disaster recovery at the household level. The model innovates by assessing the impact of disasters on people's consumption, considering asset losses and changes in income among other factors. We apply the model to quantify the effect of a hypothetical earthquake in the San Francisco Bay Area, considering the differential impact of consumption loss on poorer and richer households. The analysis reveals that poorer households suffer only $19 \%$ of the overall asset losses, but experience $41 \%$ of the well-being losses. The well-being losses extend over a larger region than that of severe asset losses, requiring design of policies to help people recover, in addition to reducing asset losses. Furthermore, we demonstrate that the effectiveness of specific policies varies across cities, depending on their built environment and social and economic profiles.
\end{abstract}

\section{Introduction}

Direct economic losses - the monetary value of damage to physical assets ${ }^{1}$ - are routinely used to measure the impact of natural disasters when they occur, and to quantify the risk posed by natural hazards. Consequently, they are the main financial metric for tracking disaster risk reduction progress. This approach generates essential insights for managing interactions among natural hazards and the built environment, in partial fulfillment of the first Priority for Action of the 2015-2030 Sendai Framework for Disaster Risk Reduction ("understanding disaster risk") ${ }^{2}$. However, direct economic losses provide an incomplete measure of the total cost of any event. Other loss dimensions include lost wages and other income, interruption of educational and health services, disruption caused by temporary or permanent relocation, and decreased consumption ${ }^{3-6}$. Furthermore, direct economic losses cannot be used to measure many of the benefits associated with the other three Sendai Priorities for Action: strengthening governance, investing in resilience, and enhancing preparedness for effective responses. At all scales, emergency preparedness, formal and informal coping mechanisms, and humanitarian relief affect the immediate and long-term consequences of disasters, even when they do not reduce direct economic losses.

Both the UN Sustainable Development Goals ${ }^{7}$ and the Sendai Framework for Disaster Risk Reduction ${ }^{2}$ call for enhanced protection of people disproportionately affected by disasters, such as the poor - another aspect that direct economic losses fail to address. By definition, wealthy individuals have the most assets to lose. Therefore, asset losses often define and proxy their experience of a shock. Conversely, the poor by definition have few assets to lose, so damage to their collective property is a small fraction of aggregate asset losses (e.g. $\left.{ }^{8}\right)$. The poor also lack the resources and instruments to smooth income shocks and recover their asset stock while maintaining pre-disaster consumption ${ }^{8,9}$. Therefore, the poor are more likely than the wealthy to forego consumption of food, health, or education, and to take longer to recover from a shock ${ }^{10-14}$.

Here we address two limitations of traditional risk assessments that focus on asset losses. First, we model the macroeconomic consequences of the disaster, assessing how damage impacts economic output in various sectors, and the implication on jobs and incomes. Second, we use well-being loss to capture the disparate effect of disasters on different socioeconomic groups throughout the recovery period. Based on classical welfare economics, well-being loss is a measure of the utility of consumption lost during household's recovery from shock ${ }^{15}$. The lost consumption includes the loss of labour income 
and housing services, cost of reconstruction, and use of resources such as savings or insurance payouts in the process of recovery.

Measuring disaster impacts with utility instead of consumption allows one to account for the differential impact of losing $\$ 1$ in consumption, as a function of wealth. While richer individuals can reduce their consumption with limited impact on their well-being, poorer individuals cannot. At the extreme, the very poor have to reduce consumption of food, education, or health care. The immediate impact of such cuts on well-being can be large, and for children can have consequences that last a lifetime $^{16,17}$.

The well-being quantification methodology in this paper integrates the three aspects of sustainability: environmental (the impact of the hazard), economic (the cost of damages and implication for jobs and income), and social (the distributional impact of the shock and the role of socioeconomic factors). It builds on previous research ${ }^{18,19}$ and uses a multi-stage simulation that explicitly quantifies damages to the built environment, post-disaster dynamics of economic sectors, and changes in household consumption across socioeconomic groups, while propagating uncertainties associated with disasters modeling. While previous approaches for evaluating disaster management policies typically focused on assessing the effect of either pre-disaster risk reduction ${ }^{20-22}$, preparedness and early warning ${ }^{23}$, or insurance ${ }^{21}$, the proposed methodology allows evaluation of policies pertaining to all stages of the disaster management cycle ${ }^{24}$.

To illustrate the methodology, we evaluate losses after an earthquake in the San Francisco Bay Area and compare the effect of several mitigation options. We show the importance of including social aspects in risk assessments: well-being losses are strongly influenced by factors other than asset damage, such as pre-disaster level of income, access to capital, and post-disaster changes in labour income. This can cause the geographic extent and severity of well-being losses to extend far beyond the distribution of direct asset losses. We also show that the results are strongly affected by whether impacts are measured via asset losses or well-being losses. Finally, we demonstrate the value of the well-being loss metric in evaluating and comparing physical and social intervention strategies. We show that the effectiveness of different strategies varies across cities, depending on their building stock, socioeconomic profile, income sources, and location relative to the hazard. No previous study has quantitatively compared regional risk mitigation strategies considering an impact metric that can be equitably applied across households with different wealth levels.

\section{Asset and well-being loss assessment}

The proposed methodology innovates by integrating four distinct models to calculate well-being losses at the household level. First, the environmental hazard (in our case, earthquake ground motion) is simulated at a regional scale for a particular event scenario. In order to take into account the uncertainty associated with spatially distributed hazard, uncertainty models that consider the joint distribution of shaking throughout the region are used to generate multiple ground motion maps ${ }^{25,26}$.

Then, for each of the ground motion maps, damage to the built environment is assessed, considering residential, commercial and industrial buildings. Damage is determined at the individual building level and uncertainty is captured by simulating the damage states with varying probabilities of occurrence. Depending on the building occupancy type and replacement cost, a damage state is translated to a repair cost (or direct loss) and time ${ }^{27}$.

Once physical damages and associated losses are simulated, their effect on the productivity of economic sectors is determined by using a dynamic adaptive regional input-output model ${ }^{18,28}$. Productivity is affected by destruction of productive capital (e.g. factories, equipment or machinery), decrease in demand due to reduced consumption, increase in demand due to reconstruction, and supply constraints caused by suppliers' inability to satisfy demand. Such post-disaster dynamics and industry inter-dependencies can cause large changes in output and gross product of the affected region, which at an individual level can result in a loss of employment and income.

Lastly, a new model that uses results from the previous three steps is used to determine well-being losses at the household level, considering its unique socioeconomic characteristics. The model builds on the approach used in the Philippines ${ }^{19}$ by explicitly considering the impact of the disaster on employment and labor income, and conducting the analysis at a high spatial resolution. This societal modeling step performs micro-simulations of the household's change in consumption over a ten year recovery period, as shown in Figure 1. Changes in consumption can result from the need to pay for housing reconstruction, loss of housing services and cost of temporary housing, and loss of labour income. Households can reduce their consumption losses by using their savings or receiving payments if they have insurance. Reconstruction and recovery of housing services depend on the severity of damages, repair time, and the ability of a household to finance the repairs. Recovery of labour income depends on the recovery of the economic sector from which the household derives its income. Finally, well-being losses are 
calculated considering the utility of consumption losses corresponding to the household's wealth level. The final metric allows one to directly compare losses across households of differing socioeconomic status, as it considers losses in terms of utility and not absolute dollar amount. Further details on four stages of the model and data sources are provided in the Methods section.

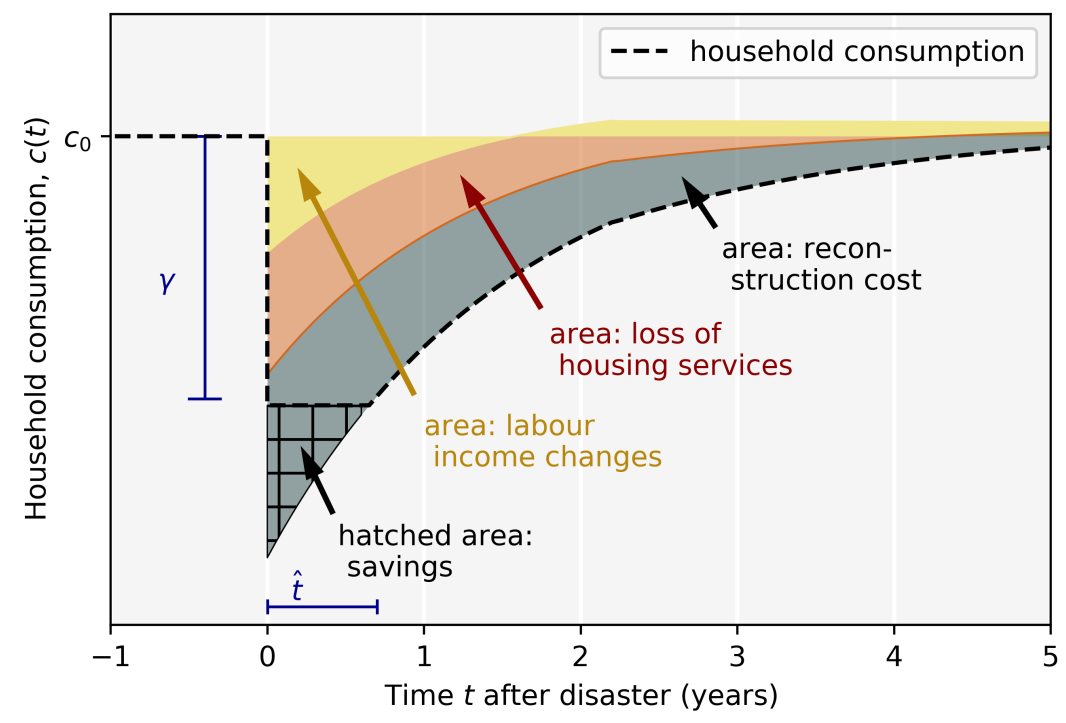

Figure 1. Schematic of the household post-disaster consumption model. $\hat{t}$ is the time interval during which savings are used to offset consumption losses and $\gamma$ is the consumption loss during that time.

\section{Study focus: San Francisco Bay Area earthquake}

In this study we consider the consequences of a large potential earthquake in the San Francisco Bay Area. The San Francisco Bay Area, also known as the Bay Area, is comprised of nine counties (see Figure 2) in Northern California and is home to over 7.6 million people. From a regional planning perspective, the area has a complex governance structure, with 101 cities, 27 transit agencies, 67 water districts, and 4 regional governance agencies. The Bay Area has a 2017 gross domestic product (GDP) of $\$ 748$ billion and is growing rapidly ${ }^{29}$. The largest sectors by value added are finance, insurance, real estate, rental, and leasing; professional and business services; and manufacturing. The largest employment sectors are educational services, health care, and social assistance; professional and business services; and manufacturing. While the GDP of the Bay Area is high, large inequalities exist and upward economic mobility is limited ${ }^{30}$. Insufficient housing supply has caused the highest increase in housing prices in the country, further contributing to inequality ${ }^{31}$.

The region is located in the middle of multiple fault zones capable of producing earthquakes of moment-magnitude $\left(\mathrm{M}_{\mathrm{w}}\right)$ greater than $6.7^{32}$. The earthquake risk in the area is exacerbated by a vulnerable building stock, low residential earthquake insurance penetration, and a large renters market raising concern over potential post-disaster out-migration. Here we analyze the impact of a $\mathrm{M}_{\mathrm{w}} 7.2$ earthquake scenario on the Hayward fault. We consider a baseline case with the current economic, insurance, and building stock conditions, and then explore the impact of a number of policy options that would affect losses.

\section{Results}

The consequences of a large earthquake in the Bay Area can be devastating. The average direct economic losses from the simulations are $\$ 115$ billion (15\% of regional GDP). This is in line with previous studies ${ }^{33}$. Most losses (56\%) occur in the housing sector, with only $7 \%$ of the these losses covered by insurance. Only $56 \%$ of residents will be liable for paying for reconstruction, because of the large renters market. Housing asset losses are concentrated around the fault rupture, where larger ground shaking is expected (Figure 3a). The most affected cities in terms of housing asset losses are Oakland, San Jose, and San Francisco (Figure 2).

Damages in the productive private sector result in an average $\$ 51$ billion of direct losses. The destruction of productive capital ripples through the economy causing an additional $\$ 35$ billion of indirect losses (or losses in value added) and it takes about 2.5 years for the regional GDP to recover. The most affected sectors in absolute terms are professional and business 
services (35\% of total indirect losses) and finance, insurance, and real estate industry (32\%). However, the most vulnerable sectors in relative terms (largest losses relative to value added) are service industries such as repair and maintenance services, personal and laundry services, and religious, grantmaking, civic, professional, and similar organizations, collectively known as 'other services', whose total losses amount to $81 \%$ of the sector's annual value added. Information on economic sector losses and the associated uncertainty is provided in the supplemental note.

The decrease in production causes an initial drop in employment of 8.7\%, and 36,200 employee-years are lost over the recovery period (around half of the jobs lost in the 1994 Northridge earthquake $^{34}$ ). Most of the lost employment is in service industries. Income losses over the recovery period are significant - on average $23 \%$ of the housing asset losses. Figure $3 \mathrm{~b}$ shows that income losses are distributed more broadly than asset losses, since employment income is related to the economic health of the entire region. In some areas, income losses can even exceed asset losses (Figure 3c). This result shows the importance of looking beyond asset losses to understand the consequences of a large disaster.

At the household level, housing asset losses tend to increase with pre-disaster income, because wealthier households tend to be homeowners with higher valued assets (Figure 4). The housing asset loss metric, however, does not indicate how the overall consumption and well-being of the household is impacted since it does not consider loss of labour income, availability of savings, the need to relocate during housing repair works, and the household's pre-disaster socioeconomic status. Well-being losses, on the other hand, do consider such factors and the trend is the opposite to that of asset losses: well-being losses sharply decrease with increasing income (Figure 4). The result reveals the disproportionate effect of disasters on lower income households (Figure 5). While households in the poorest quartile suffer only $19 \%$ of the overall asset losses, they experience $41 \%$ of the well-being losses. On the other hand, the wealthiest quartile suffers $35 \%$ of the asset losses, while experiencing only $15 \%$ of the well-being losses.

At the regional scale, well-being losses are more than double the housing asset losses, and extend beyond areas surrounding the earthquake fault rupture. Comparing Figures $3 \mathrm{a}$ and $3 \mathrm{~d}$, this is particularly evident near Concord, San Francisco, and on the east side of the San Mateo County. Considering ten largest cities in the Bay Area (Figure 2), the well-being losses exceed housing asset losses by 1.2 to 8 times, depending on factors such as the city's proximity to the fault rupture, building stock composition, income level, and predominant employment industries. The ranking of the most affected cities changes depending on the metric of choice. For instance, while Berkeley suffers more asset and labour income losses than Hayward, Hayward experiences two and a half times more well-being losses (Figure 2). This stark difference can be partly explained by the difference in pre-disaster income levels and access to savings, which affects the households' ability to recover. 
This is a non-peer reviewed preprint submitted to EarthArXiv
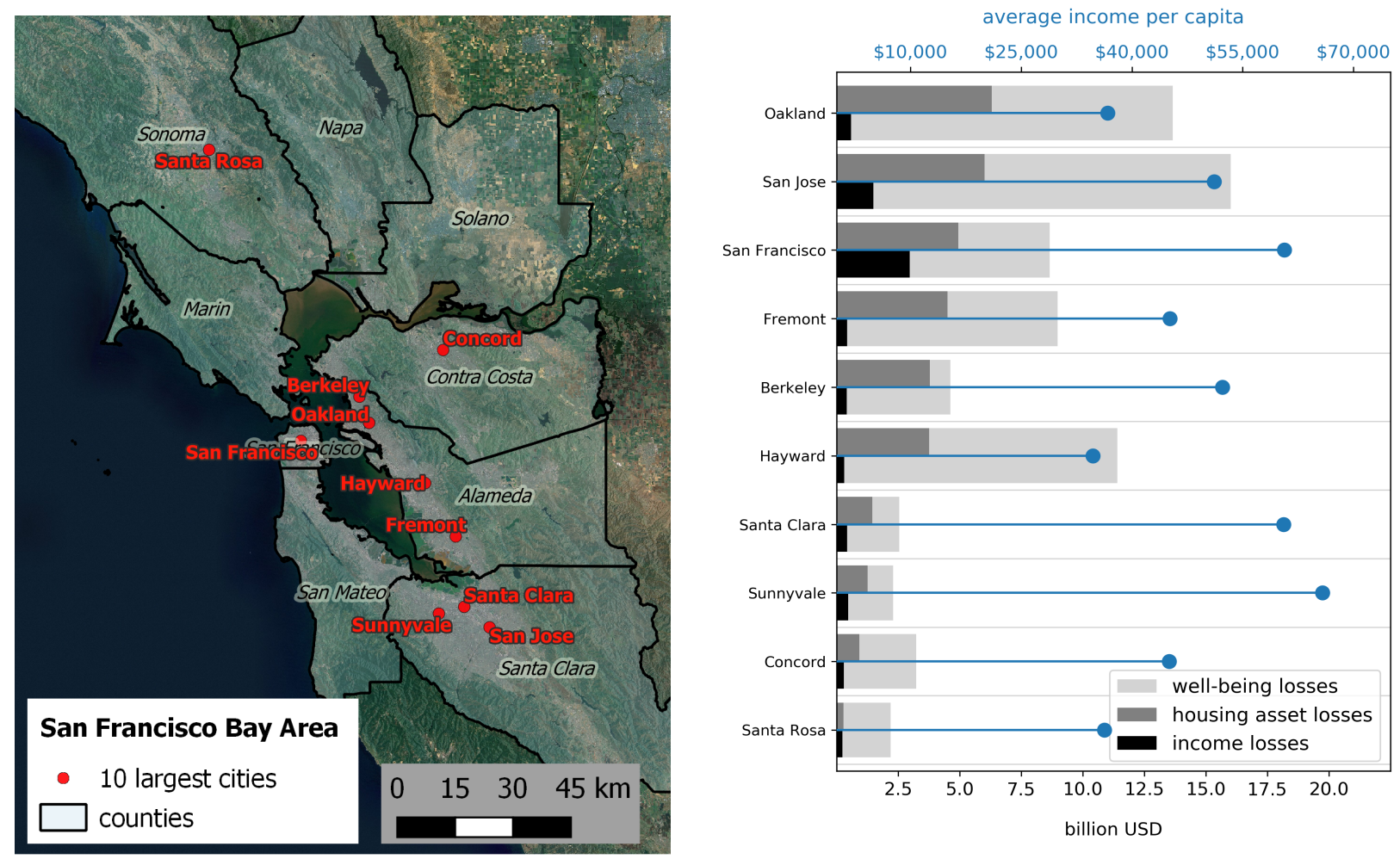

Figure 2. Map of the San Francisco Bay Area (left); losses and income per capita in the 10 largest cities, ranked by housing asset losses (right) 


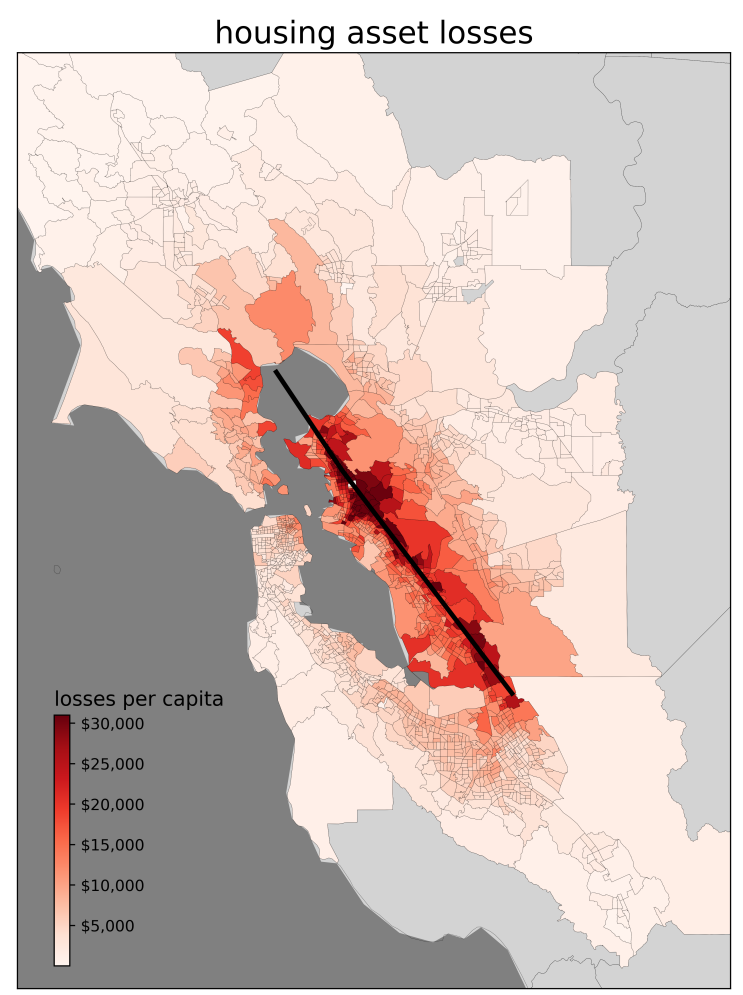

(a)

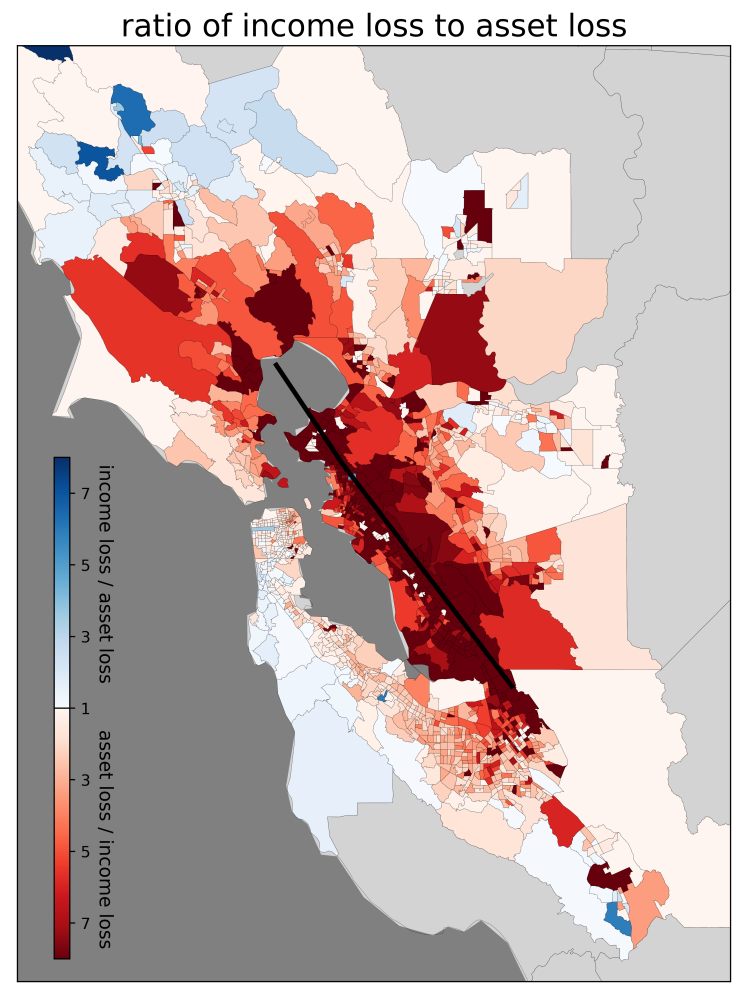

(c)

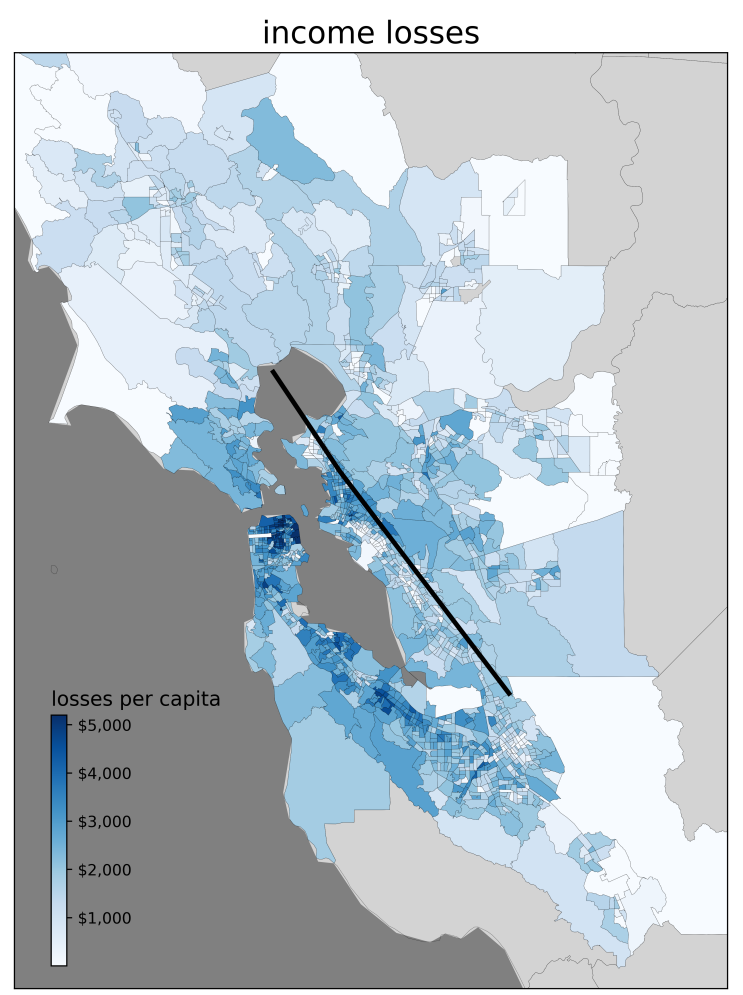

(b)

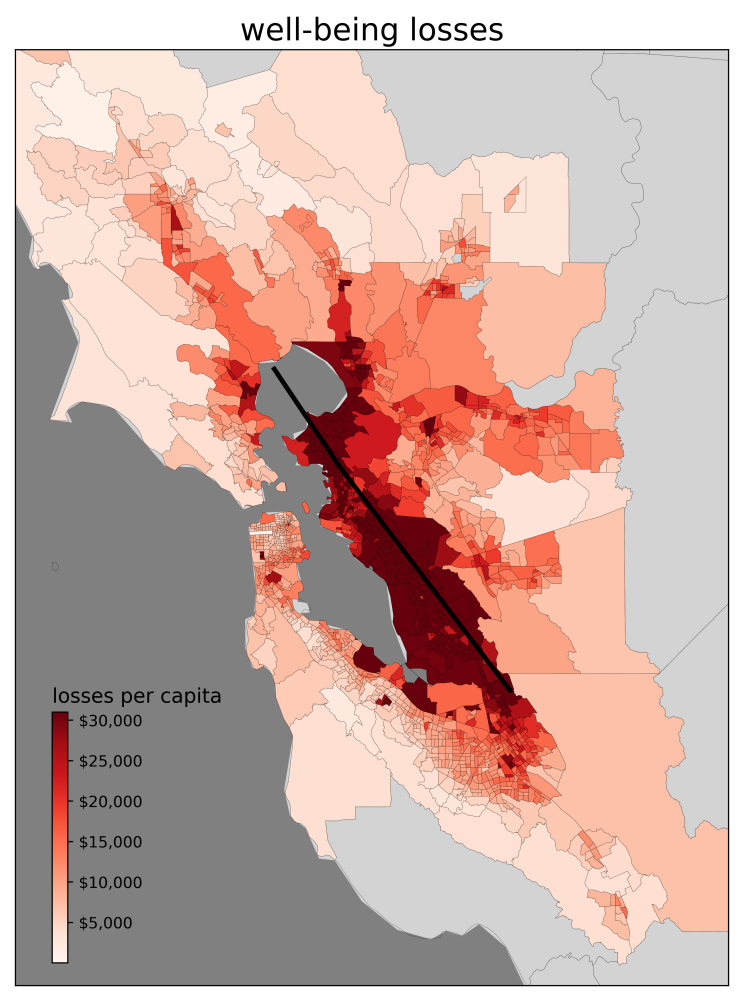

(d)

Figure 3. (a) Spatial distribution of average housing asset losses per capita; (b) spatial distribution of average income losses per capita considering a 10 year recovery period; (c) relationship of average income losses and asset losses, where in blue are areas where average income losses exceed asset losses and in red are areas where asset losses exceed income losses; (d) spatial distribution of well-being losses per capita. 

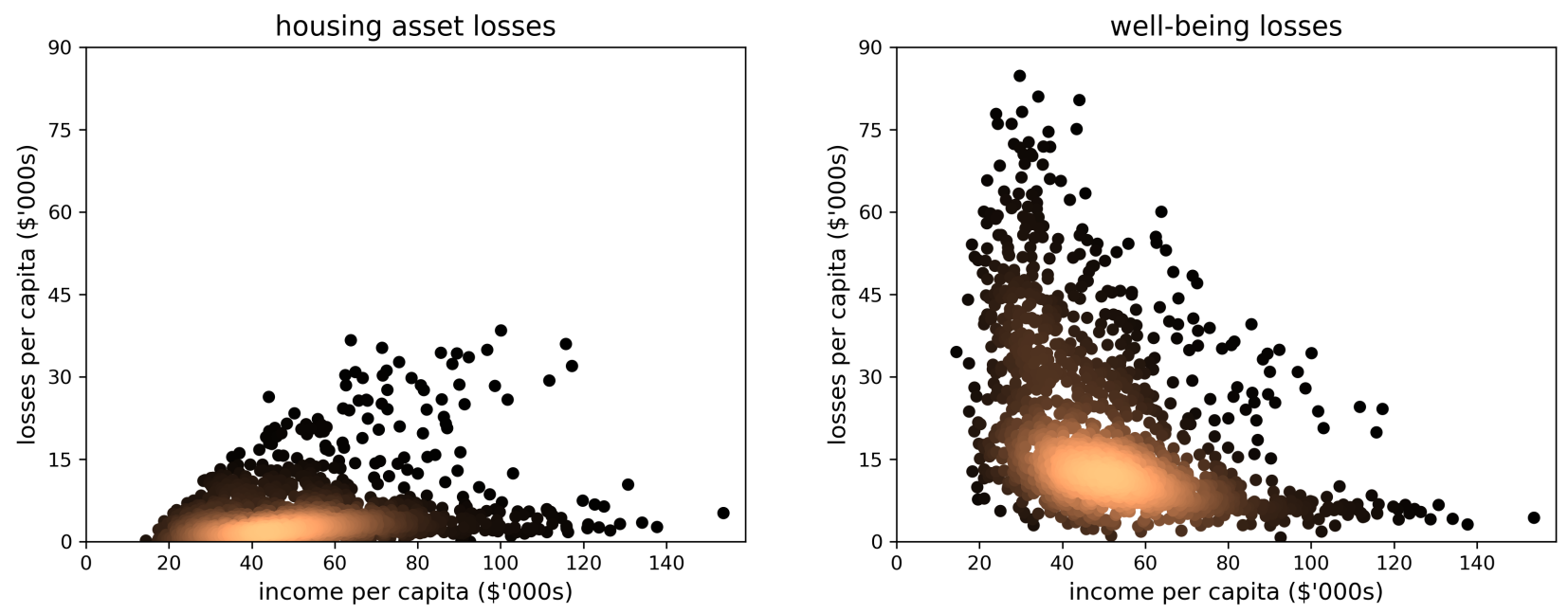

Figure 4. Distribution of average per capita housing asset losses (left) and well-being losses (right), for different pre-disaster income per capita levels.

\section{The value of risk reduction efforts}

Quantifying well-being losses allows one to evaluate both pre-disaster and post-disaster risk mitigation efforts and compare their effects across socioeconomic groups. In this case study, three risk reduction strategies are analyzed and compared: reduced building vulnerability (pre-disaster), property insurance (post-disaster), and unemployment insurance (post-disaster). Because of the differing nature of these interventions, traditional direct loss assessments do not allow this type of comparison. For each of the strategies, we compare the baseline results presented in the previous section to a counterfactual evaluation with no policy (to assess the effectiveness of existing policies), and to an enhanced policy (to assess the potential for additional risk reduction). A summary of the results is shown in Figure 6.
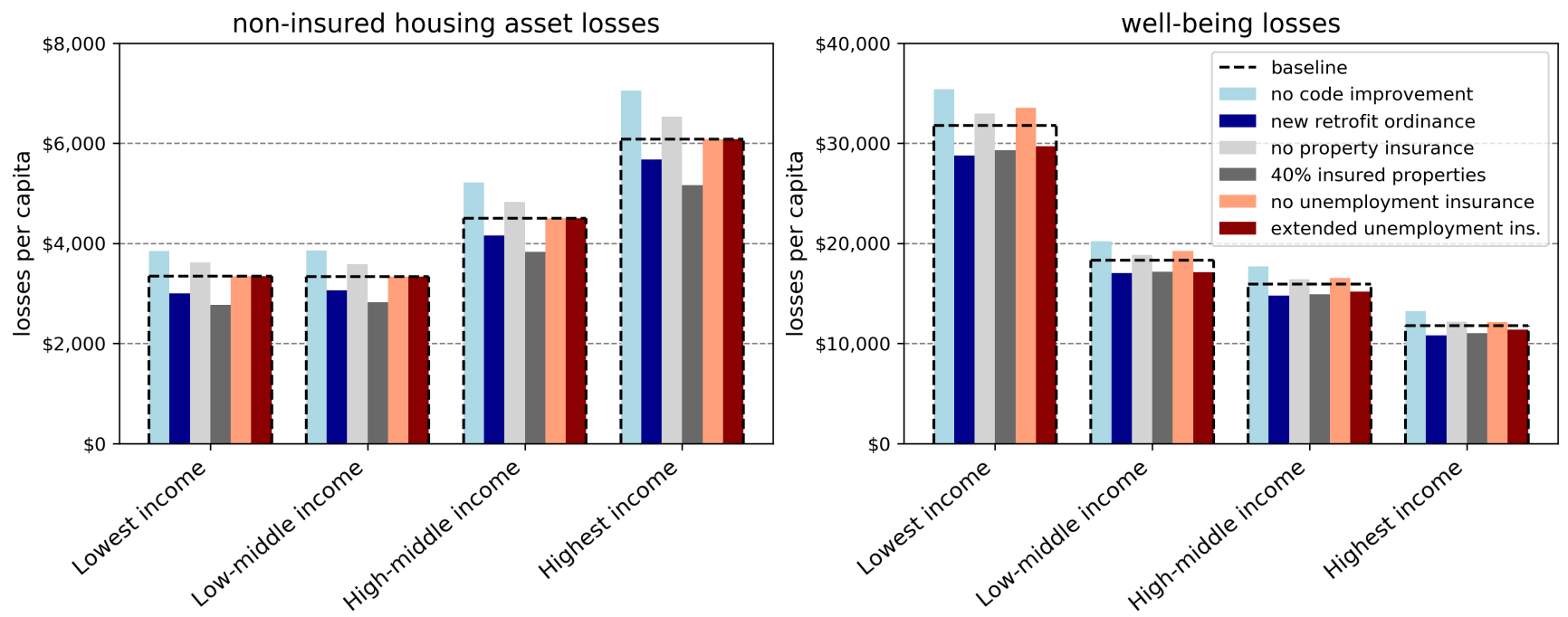

Figure 5. Effect of existing and potential future risk reduction strategies on the non-insured per capita housing asset losses (left) and per capita well-being losses (right) across different pre-disaster income categories. The income categories are defined according to income per capita $\left(i_{p c}\right) 25^{t h}, 50^{t h}, 75^{t h}$ percentiles, with the following ranges: lowest income, $i_{p c} \leq \$ 37,250 ;$ low-middle income, $\$ 37,250<i_{p c} \leq \$ 48,340$; high-middle income, $\$ 48,340<i_{p c} \leq \$ 60,410$; highest income, $i_{p c}>\$ 60,410$. 

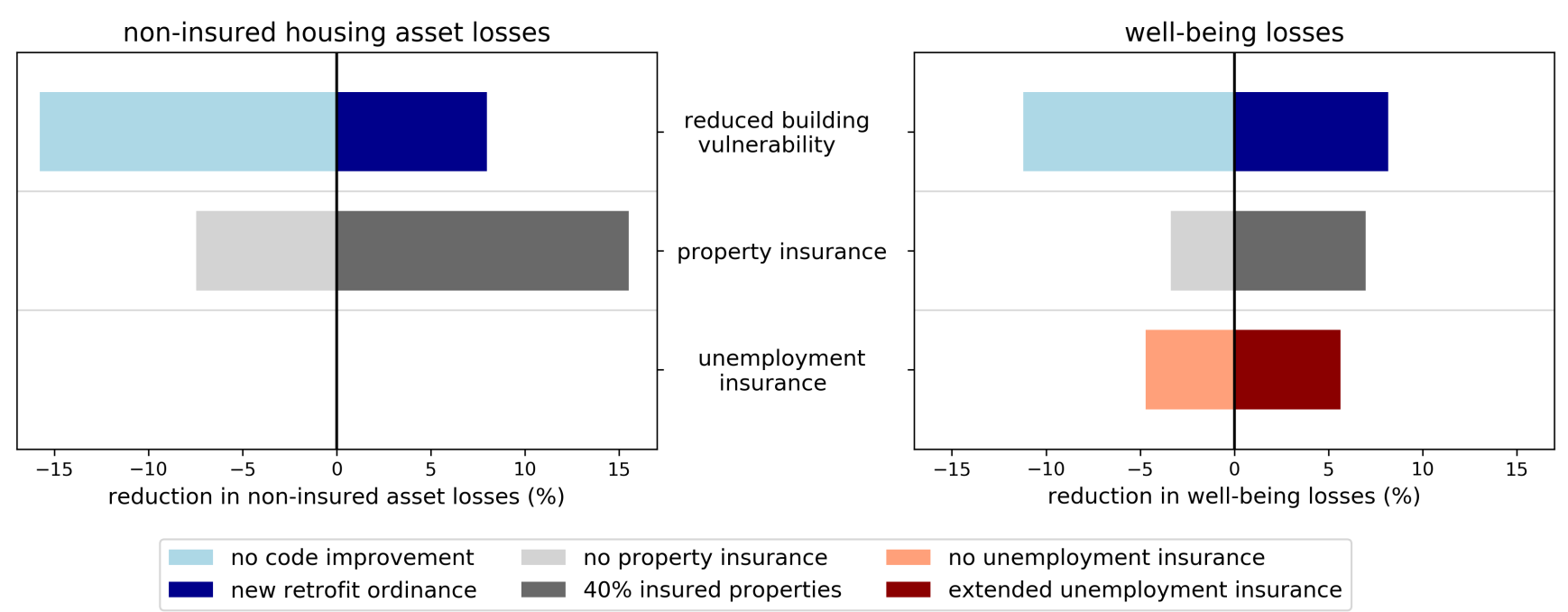

Figure 6. Effect of existing and enhanced risk reduction strategies in terms of percent reduction in housing asset losses (left) and well-being losses (right).

Reduced building vulnerability: Improving the building stock can reduce repair costs, shorten the loss of housing services and temporary relocation, and prevent loss of life in collapses (though this third benefit is not considered here). To evaluate the impact of an existing vulnerability reduction policy, we repeat the analysis assuming all newer buildings were built only to 1975 building standards (i.e. corresponding to moderate-code in $\mathrm{HAZUS}^{27}$ ). Compared to that alternative, the baseline analysis with actual new building standards decreases the average housing asset losses by $16 \%$ and well-being losses by $11 \%$. We also consider a potential future policy. This is a retrofit ordinance, where all pre-1975 apartment buildings (15\% of residential asset value) would be brought up to modern building code standards (similar to the Mandatory Seismic Retrofit Program in San Francisco ${ }^{35}$ ). Such a policy would reduce both the housing asset losses and well-being losses by $8 \%$.

Property insurance: In our baseline scenario, we assume that the percentage of the Bay Area homeowners who have earthquake insurance is the same as in the rest of California $-13 \%{ }^{36}$. Assuming that this insurance penetration is uniform across income groups, it reduces homeowners' non-insured asset losses by $8 \%$. If penetration is increased to $40 \%$, the average asset losses would further decrease by $16 \%$. This is double the reduction of non-insured asset losses as with a retrofit ordinance. The effect of non-uniform insurance penetration that depends on household wealth level is discussed in the supplemental note. While residential earthquake insurance allows property owners to decrease out-of-pocket repair costs, it does not affect repair times or well-being of renters. This can be seen in the limited effect of insurance on well-being losses (Figure 6). The current level of insurance penetration would only prevent $3 \%$ of well-being losses. By increasing insurance penetration to $40 \%$, the well-being losses could be further decreased by $7 \%$. Relative to retrofitting, insurance becomes a less effective risk reduction mechanism when considering well-being losses.

Unemployment insurance: California's Employment Development Department currently provides unemployment benefits that range from $\$ 40$ to $\$ 450$ per week for a period of up to 26 weeks for those who are eligible ${ }^{37}$. Unemployment insurance has no effect on asset losses, but can reduce well-being losses after a disaster. If all employees whose jobs were affected by the earthquake received the standard California unemployment insurance, well-being losses would be reduced by $5 \%$ on average. Extending the insurance to 1.5 years would further reduce the well-being losses by an additional $6 \%$. Extending unemployment insurance for a longer time has a decreasing marginal benefit since more people are able to return to work at later stages of the recovery. Raising the benefit amount can be an alternative strategy to further reduce well-being losses.

\section{Comparison of risk reduction efforts}

The results show the value in being able to compare the efficacy of different policies, although the cost of these remains to be assessed. The efficacy can also be evaluated for subsets of the population, offering further insights for policy makers. Figure 5 shows that the highest income quartile has the greatest non-insured housing asset loss reduction under any risk reduction policy. Conversely, the lowest income quartile has the greatest well-being benefits. Retrofitting multi-family apartment buildings in low-income areas is particularly effective, since the majority of low-income households are in this type of housing (see 
supplemental note). Increasing insurance penetration can also be effective, but only if insurance coverage is equally available to households at all socioeconomic levels. In reality, lower income households are less likely to be able to afford large investments into retrofitting or insurance premiums without government assistance. For unemployment insurance, well-being loss reduction is five times greater for lowest income group than for the highest income group, since they derive the majority of their income from wages or salaries.

\section{Risk mitigation at the city level}

Many recent seismic risk mitigation efforts have been enacted at the city level (e.g. ${ }^{35,38,39}$ ). It is therefore important for city authorities to understand the local impact of potential risk mitigation strategies as their effectiveness can differ when looking at the city-level versus the regional scale.

We see that the effectiveness of different risk reduction strategies varies across the 10 largest cities (Figure 7). In San Jose, the enhanced retrofitting, insurance and unemployment policies yield comparable reductions in losses. In San Francisco, a retrofit ordinance is much more effective than either type of insurance. This is due to San Francisco's relatively vulnerable residential building stock, and the large number of renter-occupied households who benefit from reduced recovery times of strengthened homes but not from property insurance payouts. On the other hand, in Santa Rosa a large portion of well-being losses is attributed to the loss of income, since the city is located further away from the rupture, and therefore unemployment insurance is the most effective mitigation strategy.

While a particular mitigation strategy might have been effective in the past, further efforts of the same type may not be comparably effective. For example, while Fremont's residential building stock saw large benefits from previous building code improvements, retrofitting the remaining multi-family apartment buildings to modern code standards has relatively less impact and increasing insurance penetration has more impact.
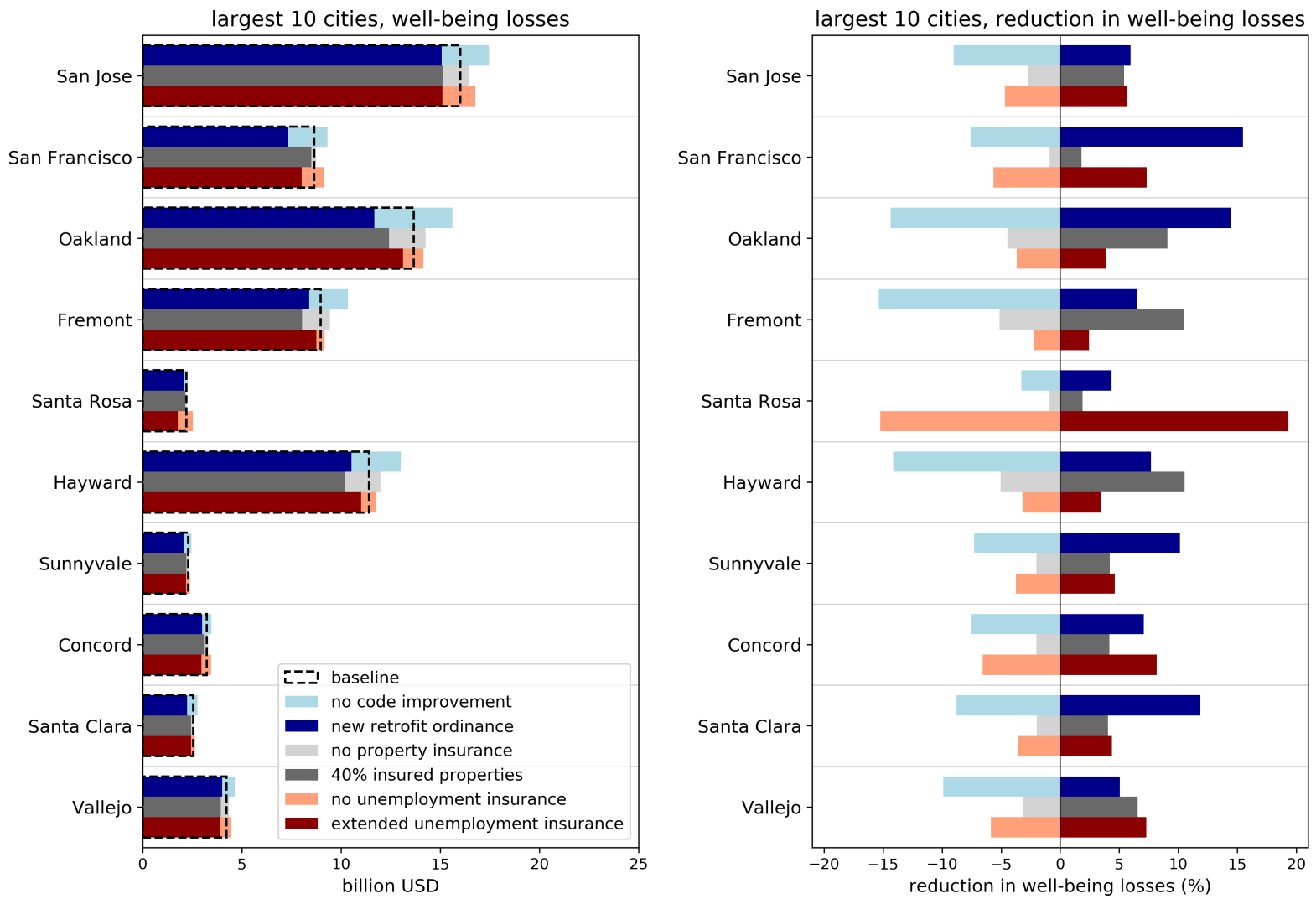

Figure 7. Effect of risk reduction strategies on the Bay Area's 10 largest cities (ordered by population) in terms of total well-being losses (left) and percent reduction in well-being losses (right). 


\section{Discussion}

Using well-being loss as opposed to asset loss as a metric to assess disaster impacts provides more insight into the consequences of a disaster throughout the recovery process. Here we measure well-being loss by integrating models at multiple spatial and temporal scales, including regional hazard simulation, building level damage and loss prediction, modeling of economic sectors' output variation, and simulation of resulting changes in household consumption.

The choice of metric to assess disaster impacts is extremely important. Choosing asset losses, as is commonly done in current practice, provides a biased representation of disaster consequences, where the wealthy appear as the most affected. However, if we consider well-being losses that take into account the utility of consumption changes throughout the recovery process, a completely different picture emerges in which the poorest quartile of the population is three times more affected than the wealthiest. This is also seen on a city level, where one city might be more affected in terms of asset losses in comparison to other cities, while being significantly less affected when considering well-being losses. Ultimately, the metric should be chosen based on the objective of the stakeholder or decision-maker. Asset loss is an appropriate metric for an insurance company. However, when we consider policies that aim to "focus on protecting the poor and people in vulnerable situations"7, well-being loss is more appropriate.

The results presented here reflect real patterns and confirm our qualitative understanding of disasters. The distribution of asset losses are driven by the spatial distribution of the hazard event and wealth and asset concentration. The housing sector is the most affected in terms of direct losses. Unemployment increases with the destruction of productive capital and produces ripple-effects in supply chains ${ }^{40-42}$. In contrast, employment increases in sectors that experience reconstruction-related demand, such as construction and manufacturing ${ }^{43}$. The impact on households extends beyond the immediate geographically affected area, where the poorer neighborhoods are disproportionately affected over the recovery period and their recovery rate is significantly slower than that of the wealthy.

When it comes to risk reduction strategies, there is no one standard solution and each community needs to design approaches based on its drivers of vulnerability, whether it is an aging building stock and infrastructure, low wealth levels, or volatile income sources. The optimal approach is likely to involve a combination of pre-disaster interventions and preparedness action to help people cope and recover from unavoidable losses ${ }^{44-46}$. The methodology proposed in this research can support the design of such a package of interventions, combining the rigor of cost-benefit analyses with consideration of socioeconomic characteristics and vulnerabilities of the affected population. 


\section{Methods}

The results presented in this paper are derived by combining several probabilistic seismic, engineering, and economic models. The four main models are summarized below:

\section{Earthquake rupture and ground motion simulation}

The earthquake rupture scenario is taken from the U.S. Geological Survey's UCERF2 Earthquake Rupture Forecast ${ }^{47}$. The Abrahamson et al. ground motion prediction equation ${ }^{25}$ is used to characterize ground motion shaking intensity throughout the Bay Area, considering factors such as distance from the rupture and local soil conditions. The uncertainty in the shaking is captured by simulating 500 ground motion maps that consider spatial correlation using a Principal Component Analysis correlation model ${ }^{26}$. The ground motion uncertainty is the largest source of uncertainty in the overall results of this model.

\section{Building infrastructure damage and direct loss modeling}

For each of the analyzed 1577 census tracts, information on the number of buildings, their occupancy, structural type, and building replacement cost is used to simulate damages for each of the 500 ground motions maps. In addition to residential buildings, the building inventory included industrial and commercial buildings that are linked to activities across different economic sectors. Fragility functions that specify the probability of various damage states (none, slight, moderate, extensive, and complete) given a level of shaking are used to model building damage. Each damage state has an associated loss ratio (repair cost as a percentage of the building replacement value) that is used to assess direct economic losses to the region. The building inventory, fragility functions, and loss ratios are taken from the U.S. national standardized methodology, HAZUS ${ }^{27}$, where the prices are adjusted to 2016 U.S. dollars.

\section{Post-disaster economic recovery modeling}

The disaster impacts on 15 economic sectors and their subsequent recovery are modeled using a modified version of the Adaptive Regional Input-Output (ARIO) macro-economic model ${ }^{18,28}$. The U.S. Bureau of Economic Analysis's (BEA's) 15 aggregated sectors are considered:

1. Agriculture, forestry, fishing, and hunting

2. Mining

3. Utilities

4. Construction

5. Manufacturing

6. Wholesale trade

7. Retail trade

8. Transportation and warehousing

9. Information

10. Finance, insurance, real estate, rental, and leasing

11. Professional and business services

12. Educational services, health care, and social assistance

13. Arts, entertainment, recreation, accommodation, and food services

14. Other services, except government

15. Government

Direct losses are assumed to be associated with damages to factories, equipment, office space, and other productive capital, which leads to a decrease in production until these damages are repaired. The decrease in each sector's productive capacity due to damages is proportional to the direct loss, using a unique average productivity of capital ratio for each sector. The average productivity of capital is derived by taking the ratio of sector's value added and fixed assets from the national BEA statistics. It is assumed that reconstruction efforts cause increased demand in construction ( $80 \%$ of the direct losses) and manufacturing (20\% of direct losses) sectors.

In addition to direct disaster impacts on a sector's production, the ARIO model captures several indirect effects spawning from industry inter-dependencies. By using a local input-output matrix for the Bay Area, the model captures output variations caused by changes in post-disaster inter-industry consumption and reconstruction demand; input scarcity resulting from suppliers' inability to meet demand; exhaustion of input inventories; and increased over-production capacity due to adaptive behavior. Over the course of the recovery, the industries' productive capacity increases as physical repairs take place and productive capital is recovered. The physical reconstruction time is constrained by the construction and manufacturing sectors' ability to satisfy reconstruction demand and physical repair times defined in HAZUS ${ }^{27}$. The model also quantifies changes in employment and labour income for each of the industries, by assuming that they are proportional to industry output throughout 
the recovery process. The ARIO model has been previously validated using Hurricane Katrina economic losses ${ }^{28}$, where changes in value added, employment, prices and profits across different industries were modeled, and has also been used to assess the impacts of the 2008 Wenchuan earthquake ${ }^{48}$.

\section{Household well-being micro-simulation}

The household model builds on Walsh and Hallegatte's socioeconomic resilience model ${ }^{19}$, but adds to it by (1) explicitly including household labour income, rent and mortgage payments, and (2) linking the household income to the impact of the disaster on jobs and labor income, as estimated by the ARIO model.

The model performs micro-simulations of households' consumption over a 10-year post-disaster recovery period, and determines changes in well-being as a result of the earthquake. In this study, one census tract represents a single household due to data resolution limitations. For each census tract, average per capita values for damages, savings, rental payments, mortgage, and income sources are calculated. These values are then assumed to be the household properties for all households in the census tract, for the purposes of computing aggregate well-being losses.

\section{Pre-disaster household model}

Capital stock: households derive income from three types of capital: (1) $k^{L}$-capital that is associated with employment and is used in the process of earning a salary or wages. This includes buildings, machinery, and equipment, where in some cases the capital is owned by the households earning the salary (e.g. small shops), and in others it is owned by other investors (e.g. owners of the factory where someone works); (2) $k^{\text {oth }}$ - other capital comprised of income-generating investments, such as financial investments; (3) $k^{h}$ - capital that provides housing services, regardless of whether this capital is owned or rented by the household. The market value of the household's residence is the sum of the land value $\left(k^{\text {land }}\right)$ and the value of the building structure $\left(k^{s t r}\right)$. The total pre-disaster capital stock $\left(k_{o}\right)$ used by the household is the following:

$$
\begin{aligned}
k_{o} & =k_{o}^{L}+k_{o}^{o t h}+k_{o}^{h} \\
& =\frac{i_{o}^{L}}{\pi}+k_{o}^{o t h}+k_{o}^{h}
\end{aligned}
$$

where $i_{o}^{L}$ is the labour income and $\pi$ is the U.S. average productivity of capital. $\pi$ is derived using Penn World Tables ${ }^{49}$.

Household income: the household's generalized income is comprised of labour income $\left(i^{L}\right)$, investment income $\left(i^{\text {oth }}\right)$, and non-monetary income associated with the receipt of housing services $\left(i^{h}\right)$. If the housing is rented, the rental payment $\left(p^{\text {rent }}\right)$ is removed from $i^{h}$ to avoid to double-counting the effective income derived from housing. The pre-disaster household income $\left(i_{o}\right)$ has the following formulation:

$$
\begin{aligned}
i_{o} & =i_{o}^{L}+i_{o}^{\text {oth }}+i_{o}^{h}-p_{o}^{r e n t} \\
& =i_{o}^{L}+\pi k_{o}^{\text {oth }}+\pi k_{o}^{h}-p_{o}^{\text {rent }}
\end{aligned}
$$

Household consumption: the pre-disaster consumption $\left(c_{o}\right)$ is equal to the pre-disaster income minus any mortgage payments $\left(p^{\text {mort }}\right)$, again to avoid double-counting housing services. We assume that the remaining income is consumed by the household in the same year and there are no financial savings, except for housing investments.

$$
c_{o}=i_{o}-p^{\text {mort }}
$$

Household well-being: at an instance in time, the utility derived from consumption is calculated using a constant relative risk aversion (CRRA) utility function, with $\eta$ the elasticity of the marginal utility of consumption (i.e., the increase in utility when consumption is increased by $\$ 1$ at one point in time). The well-being (or welfare in economics jargon) is then defined as the discounted sum of utility over time (see Equation 10).

$$
u_{0}=\frac{c_{0}^{1-\eta}}{1-\eta}
$$

\section{Post-disaster household recovery}

Capital stock: capital changes occur as a result of physical damage to buildings and infrastructure. For households, this is represented by the repair costs associated with structural and non-structural damage to their residences. The labour capital is also affected by destruction of productive capital in industries by which the household is employed. To calculate changes in 
labour capital we use labour income losses calculated in step 3 using the ARIO model. It is assumed that the other capital $\left(k^{\text {oth }}\right)$ related to investments is outside of the affected area and is unaffected by the disaster. The post-disaster capital stock, $k(t)$, at time $t$ is shown in Equation 5, where a positive $\Delta$ represents a loss; $v$ is the loss ratio which is repair cost divided by the total building value $\left(k^{s t r}\right)$; and $\lambda$ is the household's reconstruction rate determined by Equation 12.

$$
\begin{aligned}
k(t) & =k_{o}-\left(\Delta k^{L}(t)+\Delta k^{h}(t)\right) \\
& =k_{o}-\left(\frac{\Delta i^{L}(t)}{\pi}+v k^{h} e^{-\lambda t}\right)
\end{aligned}
$$

Household income: post-disaster income changes are derived from the changes in capital stock. In the case where a specific industry is over-producing to meet the increased reconstruction demand, labour income can actually increase, resulting in a negative $\Delta i^{L}(t)$. It is also assumed that renters will not have to keep paying the full rent for a damaged property, and therefore the rental payments will decrease proportionally to the asset value.

$$
\begin{aligned}
i(t) & =i_{o}-\Delta i(t) \\
& =i_{o}-\left(\Delta i^{L}(t)+\pi \Delta k^{h}(t)-\Delta p^{r e n t}(t)\right) \\
& =i_{o}-\left(\Delta i^{L}(t)+\pi v k_{o}^{h} e^{-\lambda t}-v p_{o}^{r e n t} e^{-\lambda t}\right)
\end{aligned}
$$

Household consumption: post-disaster consumption is affected by changes in income and the need to pay for reconstruction of physical assets owned by the households. In addition, households can use their savings to make up for the decrease in consumption. Post-disaster consumption, $c(t)$, is illustrated in Figure 1 and is expressed in Equation 7.

$$
c(t)=\max \left\{c_{o}-\Delta c(t), \quad c_{o}-\gamma\right\}
$$

where

$$
\begin{aligned}
\Delta c(t) & =\Delta i(t)+c_{\text {reco }}(t) \\
& =\left(\Delta i^{L}(t)+\pi v k_{o}^{h} e^{-\lambda t}-v p_{o}^{r e n t} e^{-\lambda t}\right)+\lambda v k^{s t r} f^{o} e^{-\lambda t}
\end{aligned}
$$

where $c_{\text {reco }}(t)$ is the repair cost at time $t ; \gamma$ is the consumption loss considering the use of savings, which is found using Equation 9; and $f^{o}$ is the fraction of owner-occupied households. The post-disaster consumption remains constant at level $c_{o}-\gamma$ until time $\hat{t}$ when savings are depleted. Both the asset and income losses are adjusted to consider payments from property and unemployment insurance. We also assume that reconstruction of rented residences is financed by investors (owners) who live outside of the disaster area. Therefore repair costs associated with rented residences do not affect household consumption in the affected area. Assuming that all owners of the rented residences are outside of the region is a simplification, which can lead to underestimation of impacts on households that own rental properties. However, more granular modeling is impossible at this stage due to the absence of data on the localization of rental property owners.

$$
\{\gamma, \hat{t}\} \text { s.t }\left\{\begin{array}{l}
\gamma=\Delta c(\hat{t}) \\
\gamma \hat{t}+\text { savings }=\int_{0}^{\hat{t}} \Delta c(t) d t
\end{array}\right.
$$

Well-being losses: we define well-being losses as the present value of the change in utility from pre-disaster level over the recovery period, $T$, using continuous discounting and a utility discount rate $\rho$, which is assumed to equal to 10 percent. The discount rate is calibrated such that the pre-disaster situation is optimal, with the marginal productivity of capital equal to the consumption discount rate. The marginal productivity of capital is classically estimated assuming a Cobb-Douglas production function, as the product of the average productivity of capital (the ratio of the output to capital stock) and the share of profit in total income (assumed equal to 30 percent). Equation 10 shows the model formulation.

$$
\begin{aligned}
\Delta W & =\int_{0}^{T}\left(u_{o}-u(t)\right) e^{-\rho t} d t \\
& =\int_{0}^{T}\left(\frac{c_{o}^{1-\eta}}{1-\eta}-\frac{c(t)^{1-\eta}}{1-\eta}\right) e^{-\rho t} d t
\end{aligned}
$$

Finally, since the units in Equation 10 are non-monetary and not easy to interpret, we convert $\Delta W$ into an equivalent consumption change, $\Delta C_{e q}$ (see Equation 11). The equivalent consumption change represents the dollar amount by which a 
household earning the mean Bay Area income would have to decrease its consumption to experience the same well-being decrease as the considered household. The final change in equivalent consumption is what we refer to as well-being loss. This process is equivalent to scaling up losses affecting poor people and scaling down losses affecting rich people, such that a $\$ 1$ loss in well-being has the same impact on the high and low income population.

$$
\Delta C_{e q}=\Delta W /\left.\frac{d W}{d c_{o}}\right|_{c_{\text {mean }}}
$$

Reconstruction rate optimization and constraints: the household reconstruction rate is a minimum of three rates: the physical reconstruction rate $^{27}$; the reconstruction rate that maximizes the household well-being over 10 years, taking into account that the household might prefer to defer reconstruction to maintain its consumption level; the reconstruction rate that the household can afford while retaining sufficient consumption to avoid extreme poverty. The mathematical formulation is shown in Equation 12.

$$
\lambda=\min \left\{\lambda_{\text {hazus }}, \lambda_{\text {opt }}, \lambda_{\text {pov }}\right\}
$$

where

$$
\lambda_{\text {opt }}=\underset{\lambda_{\text {opt }}}{\operatorname{argmax}} \int_{0}^{T} \frac{1}{1-\eta}\left(c_{o}-\left(\Delta i^{L}(t)+\pi v k_{o}^{h} e^{-\lambda_{\text {opt }} t}-v p_{o}^{r e n t} e^{-\lambda_{\text {opt }} t}\right)-\lambda_{\text {opt }} v k^{s t r} f^{o} e^{-\lambda_{\text {opt }} t}\right)^{1-\eta} d t
$$

\section{Model limitations}

Several limitations should be highlighted for consideration in future research. In this model, damages to lifelines such as road, water, power and telecommunication networks are not explicitly modeled due to lack of data. Other studies predict that a similar size earthquake $\left(M_{w}\right.$ 7.0) would cause damage to the water network, where 30-95\% of service would be returned within 7 days depending on the county, and full service within 30-210 days ${ }^{33}$. In addition, damage due to secondary hazards such as fire, liquefaction and landslides is not modeled. Post-earthquake fire can be a significant source of loss, where the aforementioned study estimates a $\$ 16$ billion loss in terms of building replacement value. Considering these damages in our model would further increase both asset and well-being losses.

The economic recovery model used in this study makes several simplifications. First, the assumption that each sector is homogeneous can lead to underestimating supply chain disruptions linked to specific products or services. It can also lead to underestimating the ability of firms to cope with the impact of the disaster ${ }^{22,50}$. Second, the assumption that the impact on jobs is proportional to the impact on value added can underestimate job losses (for instance when a small firm loses half of its capacity and goes bankrupt) or overestimate job losses (for instance when a large firm loses production capacity but keep its workers during the recovery phase). Third, the model assumes that the economy is in a state of equilibrium prior to disaster, and returns to this state during the recovery. In reality, post-reconstruction economies are sometimes significantly different from pre-disaster ones ${ }^{51}$. Finally, the macroeconomic impact of the disaster depends on the stage of the business cycle. Previous research suggests that if the economy is in the expansion stage the losses are amplified, and if it is in the recession stage the losses are dampened through the mobilization of idle resources ${ }^{52}$.

At the household level, the model makes several simplifications, largely forced by data availability. Informal support from friends and family after a disaster is not considered, and households are assumed to determine their reconstruction rate optimally. Also, it is assumed that the loss of housing service provided by a home is linearly related to the damages, while in reality dwellings become impossible to use if damages are too extensive. Also, permanent relocation of households within and outside of the affected area is not considered. Previous studies show that disasters often lead to short-term migration and in some cases long-term migration patterns, which can significantly affect labour supply and wages in both the affected area and in-migration regions ${ }^{4}$. Household decisions to relocate depend on factors such as the type of affected area (urban or rural) and socioeconomic status, where more educated and wealthier individuals in urban areas are more likely to relocate following a disaster. Renters can also relocate more easily given their mobility. This could be a concern in the Bay Area given its wealth distribution and high percentage of renters, and should be investigated further.

Lastly, in this study information on households is aggregated at the census tract level due to data availability limitations. A census tract is a geographic delineation that typically has population size between 1200 and 8000 people, with an average size of 4000. While using census tracts preserves the geographic distribution of damage, this averaging will impact household characteristics in highly heterogeneous areas. A way to mitigate this in the future is to either use a more suitable household 
survey where information on spatial and demographic distribution is preserved, or generate synthetic population data through spatial micro-simulation modeling ${ }^{53}$.

\section{Data sources}

This research and modeling approach used exposure data from U.S. Federal Emergency Management Agency's HAZUS; socioeconomic and demographic statistics from U.S. Census and American Community Survey through the Simply Analytics platform; trade statistics from U.S. Census Import and Export Merchandise; national and regional industry data from U.S. Bureau of Economic Analysis and Regional Input-Output Modeling System (RIMS II); and labour statistics from U.S. Bureau of Labour Statistics. Year 2016 is taken as the base year where the data is available.

\section{References}

1. United Nations International Strategy for Disaster Reduction (UNISDR). Terminology of disaster risk reduction. https: //www.unisdr.org/we/inform/terminology (2017).

2. United Nations (UN). Sendai framework for disaster risk reduction 2015-2030. (2015).

3. Sawada, Y. \& Shimizutani, S. How do people cope with natural disasters? Evidence from the Great Hanshin-Awaji (Kobe) Earthquake in 1995. Journal of Money, Credit and Banking 40, 463-488, DOI: 10.1111/j.1538-4616.2008.00122.x (2008). https://onlinelibrary.wiley.com/doi/pdf/10.1111/j.1538-4616.2008.00122.x.

4. Belasen, A. R. \& Polachek, S. W. International Handbook on the Economics of Migration (Edward Elgar Publishing, 2013).

5. Jacques, C. C. et al. Resilience of the canterbury hospital system to the 2011 christchurch earthquake. Earthq. Spectra 30, 533-554, DOI: 10.1193/032013EQS074M (2014). https://doi.org/10.1193/032013EQS074M.

6. Potter, S., Becker, J., Johnston, D. \& Rossiter, K. An overview of the impacts of the 2010-2011 canterbury earthquakes. Int. J. Disaster Risk Reduct. 14, 6 - 14, DOI: https://doi.org/10.1016/j.ijdrr.2015.01.014 (2015). The 2010-2011 Canterbury Earthquake Sequence: Personal, Social, Governance and Environmental Consequences.

7. United Nations (UN). Transforming our world: The 2030 agenda for sustainable development. Div. for Sustain. Dev. Goals (2015).

8. Carter, M. R., Little, P. D., Mogues, T. \& Negatu, W. Poverty traps and natural disasters in ethiopia and honduras. World development 35, 835-856 (2007).

9. Howell, J. \& Elliott, J. R. As disaster costs rise, so does inequality. Socius 4, 2378023118816795, DOI: 10.1177/ 2378023118816795 (2018). https://doi.org/10.1177/2378023118816795.

10. Peacock, W. G., Van Zandt, S., Zhang, Y. \& Highfield, W. E. Inequities in long-term housing recovery after disasters. $J$. Am. Plan. Assoc. 80, 356-371 (2014).

11. Davidson, T. M., Price, M., McCauley, J. L. \& Ruggiero, K. J. Disaster impact across cultural groups: Comparison of Whites, African Americans, and Latinos. Am. journal community psychology 52, 97-105 (2013).

12. Donner, W. \& Rodríguez, H. Population composition, migration and inequality: The influence of demographic changes on disaster risk and vulnerability. Soc. forces 87, 1089-1114 (2008).

13. Masozera, M., Bailey, M. \& Kerchner, C. Distribution of impacts of natural disasters across income groups: A case study of New Orleans. Ecol. Econ. 63, 299-306 (2007).

14. Fothergill, A. \& Peek, L. A. Poverty and disasters in the united states: A review of recent sociological findings. Nat. Hazards 32, 89-110, DOI: 10.1023/B:NHAZ.0000026792.76181.d9 (2004).

15. Hallegatte, S., Vogt-Schilb, A., Bangalore, M. \& Rozenberg, J. Unbreakable: building the resilience of the poor in the face of natural disasters (World Bank, 2016).

16. Behrman, J. R. The impact of health and nutrition on education. The World Bank Res. Obs. 11, 23-37 (1996).

17. Glewwe, P., Jacoby, H. G. \& King, E. M. Early childhood nutrition and academic achievement: a longitudinal analysis. J. Public Econ. 81, 345 - 368, DOI: https://doi.org/10.1016/S0047-2727(00)00118-3 (2001).

18. Hallegatte, S. Modeling the role of inventories and heterogeneity in the assessment of the economic costs of natural disasters. Risk analysis 34, 152-167 (2014).

19. Walsh, B. \& Hallegatte, S. Measuring natural risks in the Philippines: Socioeconomic resilience and wellbeing losses. World Bank Policy Res. Work. Pap. (2019). 
20. Chang, S. E. \& Shinozuka, M. Measuring improvements in the disaster resilience of communities. Earthq. Spectra 20, 739-755, DOI: 10.1193/1.1775796 (2004). https://doi.org/10.1193/1.1775796.

21. Grossi, P. Catastrophe modeling: a new approach to managing risk, vol. 25 (Springer Science \& Business Media, 2005).

22. Rose, A. \& Liao, S.-Y. Modeling regional economic resilience to disasters: A computable general equilibrium analysis of water service disruptions*. J. Reg. Sci. 45, 75-112, DOI: 10.1111/j.0022-4146.2005.00365.x (2005). https://onlinelibrary. wiley.com/doi/pdf/10.1111/j.0022-4146.2005.00365.x.

23. Dawson, R. J., Peppe, R. \& Wang, M. An agent-based model for risk-based flood incident management. Nat. hazards 59, 167-189 (2011).

24. Alexander, D. E. Principles of emergency planning and management (Oxford University Press on Demand, 2002).

25. Abrahamson, N. A., Silva, W. J. \& Kamai, R. Summary of the ASK14 ground motion relation for active crustal regions. Earthq. Spectra 30, 1025-1055, DOI: 10.1193/070913EQS198M (2014). https://doi.org/10.1193/070913EQS198M.

26. Markhvida, M., Ceferino, L. \& Baker, J. W. Modeling spatially correlated spectral accelerations at multiple periods using principal component analysis and geostatistics. Earthq. Eng. \& Struct. Dyn. 47, 1107-1123 (2018).

27. FEMA. HAZUS MH-2.1 Earthquake Model Technical Manual (Federal Emergency Management Agency Washington, DC, 2015).

28. Hallegatte, S. An adaptive regional input-output model and its application to the assessment of the economic cost of Katrina. Risk analysis 28, 779-799 (2008).

29. Bay Area Council Economic Institute. Bay area economic profile: Continuing growth and unparalleled innovation. Tech. Rep. 10, Bay Area Council Economic Institute (2018).

30. Terplan, E. et al. Economic prosperity strategy: Improving economic opportunity for the bay area's low- and moderate-wage workers. Tech. Rep., San Francisco Bay Area Planning and Urban Research Association (SPUR) (2014).

31. Metcalf, G. et al. Four future scenarios for the san francisco bay area. The Urban. (2018).

32. Field, E. H. \& 2014 Working Group on California Earthquake Probabilities. Ucerf3: A new earthquake forecast for california's complex fault system. Tech. Rep., U.S. Geological Survey (2015). DOI: https://dx.doi.org/10.3133/fs20153009.

33. Detweiler, S. T. \& Wein, A. M. The haywired earthquake scenario-engineering implications. Tech. Rep., Reston, VA (2018). Report.

34. Petak, W. J. \& Elahi, S. The Northridge earthquake, USA and its economic and social impacts. In Proceedings of EuroConference on Global Change and Catastrophe Risk Management (IIASA, 2000).

35. San Francisco Board of Supervisors. Ordinance no. 66-13, building code - mandatory seismic retrofit program - wood-frame buildings; optional evaluation form fee (2013). https://sfbos.org/ftp/uploadedfiles/bdsupvrs/ordinances13/o0066-13.pdf.

36. Fuller, T. In quake-prone California, alarm at scant insurance coverage. New York Times (2013).

37. State of California Employment Development Department. A guide to benefits and employment services. Tech. Rep. DE 1275A Rev.49.

38. Los Angeles City Council. Ordinance no. 183893 (2015).

http://ladbs.org/docs/default-source/publications/misc-publications/ordinance_183893.pdf?sfvrsn=6.

39. City of Berkeley. Berkeley Municipal Code, Chapter 19.39 (Berkeley, 2005).

40. Murlidharan, T. \& Shah, H. Economic consequences of catastrophes triggered by natural hazards. Ph.D. thesis, Stanford University (2003).

41. Howe, C. W. \& Cochrane, H. C. Guidelines for the uniform definition, identification, and measurement of economic damages from natural hazard events: With comments on historical assets, human capital, and natural capital. (1993).

42. Rose, A. Economic principles, issues, and research priorities in hazard loss estimation. In Modeling spatial and economic impacts of disasters, 13-36 (Springer, 2004).

43. Ewing, B. T., Kruse, J. B. \& Thompson, M. A. Twister! employment responses to the 3 may 1999 oklahoma city tornado. Appl. Econ. 41, 691-702 (2009).

44. Cohen, O., Goldberg, A., Lahad, M. \& Aharonson-Daniel, L. Building resilience: The relationship between information provided by municipal authorities during emergency situations and community resilience. Technol. Forecast. Soc. Chang. 121, 119-125 (2017). 
45. Imperiale, A. J. \& Vanclay, F. Experiencing local community resilience in action: Learning from post-disaster communities. J. Rural. Stud. 47, 204 - 219, DOI: https://doi.org/10.1016/j.jrurstud.2016.08.002 (2016).

46. Mechler, R. et al. Managing unnatural disaster risk from climate extremes. Nat. Clim. Chang. 4, 235 (2014).

47. Field, E. H. et al. Uniform California Earthquake Rupture Forecast, Version 2 (UCERF 2). Bull. Seismol. Soc. Am. 99, 2053-2107, DOI: $<$ p $>10.1785 / 0120080049</ p>(2009)$.

48. Wu, J. et al. Regional indirect economic impact evaluation of the 2008 wenchuan earthquake. Environ. Earth Sci. 65, 161-172 (2012).

49. Feenstra, R. C., Inklaar, R. \& Timmer, M. P. The next generation of the Penn World Table. Am. Econ. Rev. 105, 3150-3182 (2015).

50. Dormady, N., Roa-Henriquez, A. \& Rose, A. Economic resilience of the firm: A production theory approach. Int. J. Prod. Econ. 208, 446 - 460, DOI: https://doi.org/10.1016/j.ijpe.2018.07.017 (2019).

51. Coffman, M. \& Noy, I. Hurricane iniki: measuring the long-term economic impact of a natural disaster using synthetic control. Environ. Dev. Econ. 17, 187-205, DOI: 10.1017/S1355770X11000350 (2012).

52. Hallegatte, S. \& Ghil, M. Endogenous Business Cycles and the Economic Response to Exogenous Shocks. SSRN Electron. J. DOI: $10.2139 / \mathrm{ssrn} .968378$ (2007).

53. Hermes, K. \& Poulsen, M. A review of current methods to generate synthetic spatial microdata using reweighting and future directions. Comput. Environ. Urban Syst. 36, 281-290 (2012).

54. Grace, M. F., Klein, R. W. \& Kleindorfer, P. R. The demand for homeowners insurance with bundled catastrophe coverages. Tech. Rep., Working Paper Series: Finance \& Accounting (2001). 


\section{SUPPLEMENTAL NOTE}

The supplemental note provides additional information on results and further analysis.

\section{Baseline results}

Figure 8 shows how the type of housing changes with increasing income. In general, lower income households tend to live in multi-family apartment buildings. As income increases, the majority of households $(\sim 70 \%)$ live in single-family homes.

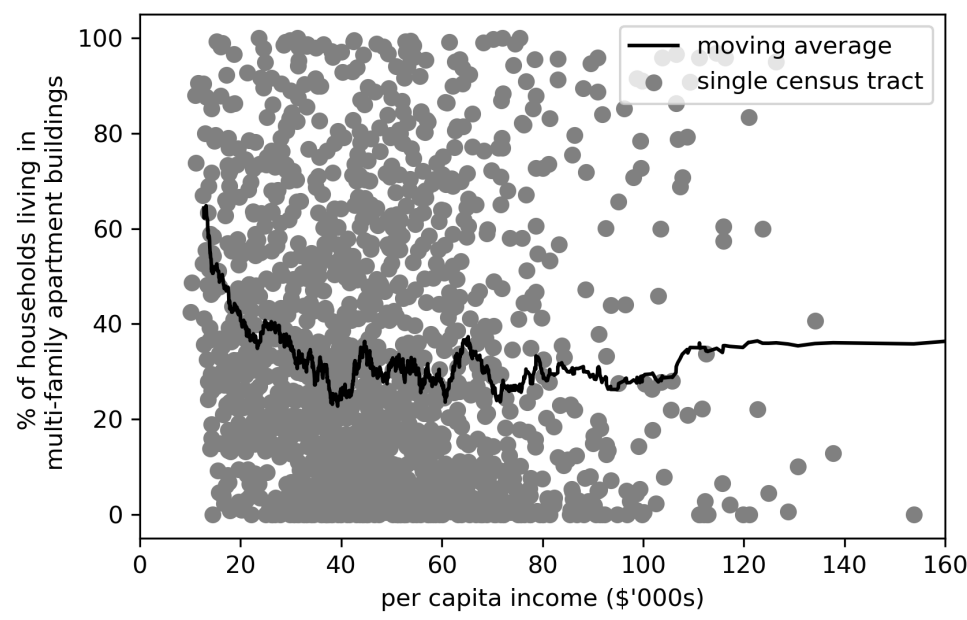

Figure 8. Percent of households living in multi-family apartment buildings at different levels of income per capita.

Looking at the distribution of loss ratios (repair cost divided by replacement value of the building) shown in Figure 9, we can see that lower income areas experience higher loss ratios and are more vulnerable. Areas with average per capita income greater than $\$ 40,000$ on average experience similar loss ratios.

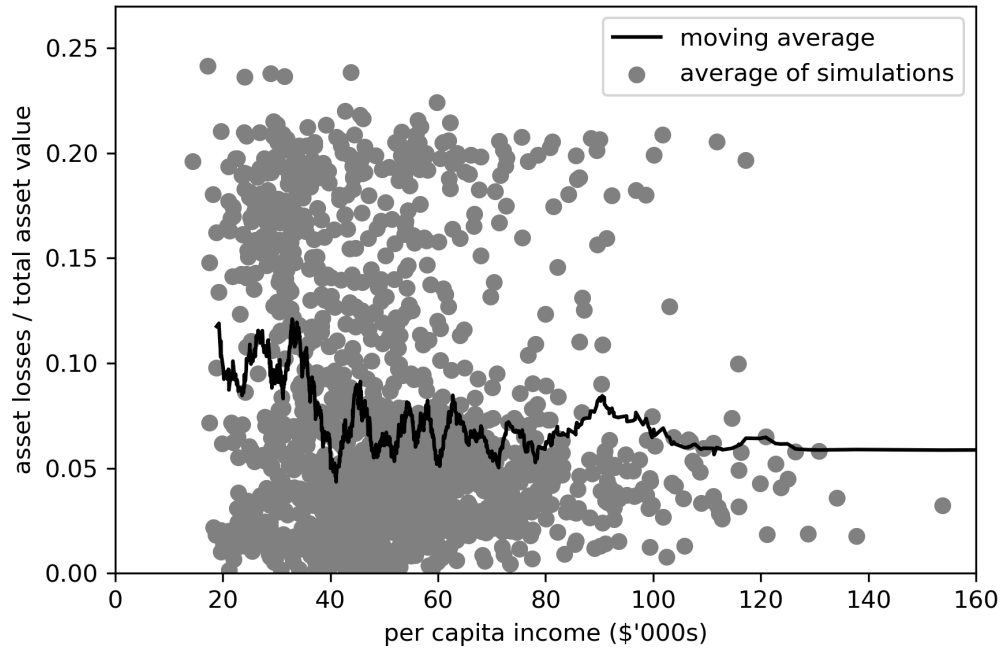

Figure 9. Distribution of loss ratios (repair cost divided by replacement value of the building) at different levels of income per capita. Loss ratio is a function of the building type and its vulnerability as well as the level of hazard, i.e., ground shaking. Each grey point is the average loss ratio for a single census tract.

Results for each of the economic sectors in economic recovery modeling (step 3 of the model) are summarized in Table 1. 
This is a non-peer reviewed preprint submitted to EarthArXiv

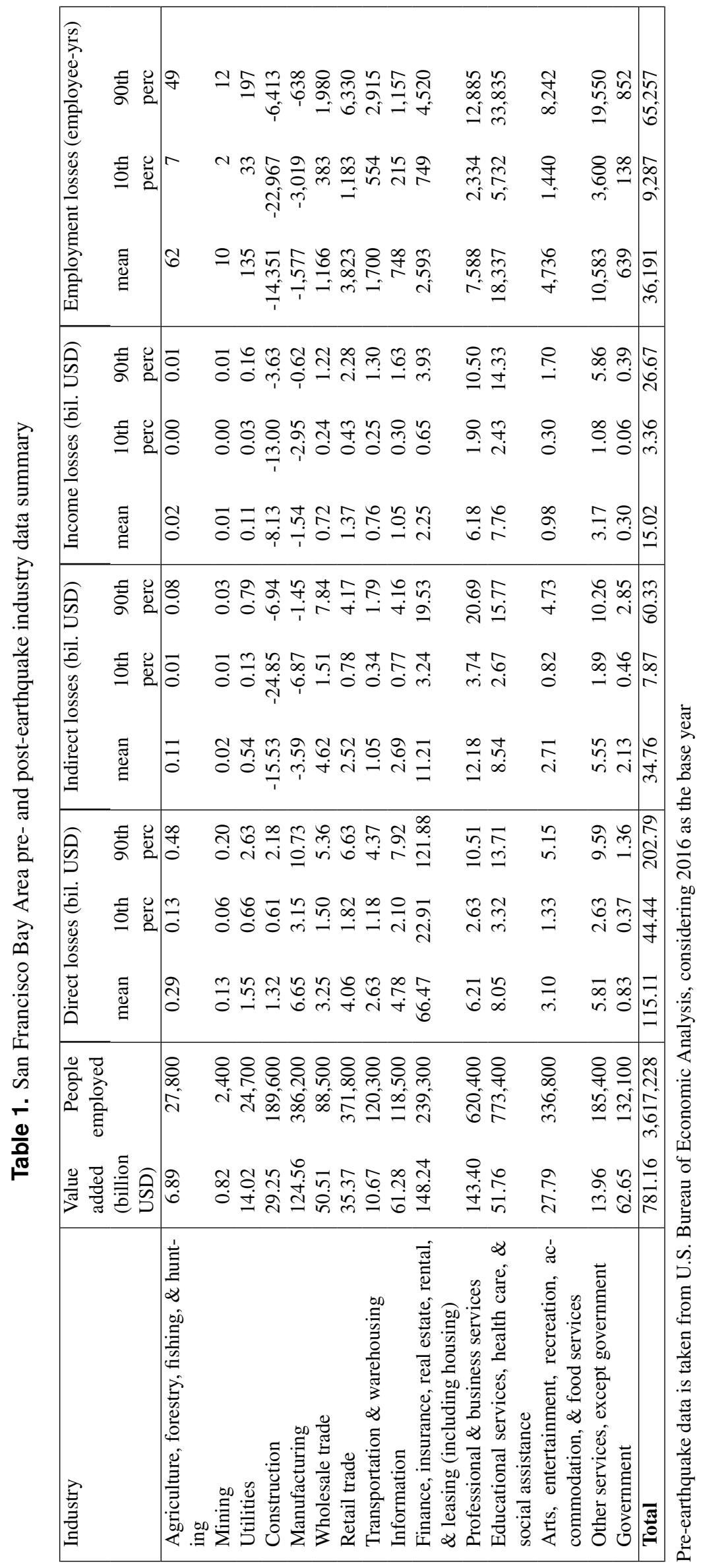




\section{Summary of risk reduction strategies}

Table 2 summarizes the effect of different risk reduction mechanisms on both non-insured housing asset losses and well-being losses across income quartiles.

Table 2. Loss changes due to existing and potential future risk reduction efforts

\begin{tabular}{|c|c|c|c|c|c|c|c|c|c|c|}
\hline \multirow[t]{2}{*}{ Policy } & \multicolumn{5}{|c|}{ Housing asset loss change (per capita) } & \multicolumn{5}{|c|}{ Well-being loss change (per capita) } \\
\hline & $\begin{array}{l}\text { Lowest } \\
\text { income }\end{array}$ & $\begin{array}{l}\text { Low- } \\
\text { middle } \\
\text { income }\end{array}$ & $\begin{array}{l}\text { High- } \\
\text { middle } \\
\text { income }\end{array}$ & $\begin{array}{l}\text { Highest } \\
\text { income }\end{array}$ & Overall & $\begin{array}{l}\text { Lowest } \\
\text { income }\end{array}$ & $\begin{array}{l}\text { Low- } \\
\text { middle } \\
\text { income }\end{array}$ & $\begin{array}{l}\text { High- } \\
\text { middle } \\
\text { income }\end{array}$ & $\begin{array}{l}\text { Highest } \\
\text { income }\end{array}$ & Overall \\
\hline $\begin{array}{l}\text { no code improve- } \\
\text { ment }\end{array}$ & $\begin{array}{l}\$ 510 \\
(15.3 \%)\end{array}$ & $\begin{array}{l}\$ 520 \\
(15.8 \%)\end{array}$ & $\begin{array}{l}\$ 720 \\
(15.9 \%)\end{array}$ & $\begin{array}{l}\$ 970 \\
(16.0 \%)\end{array}$ & $\begin{array}{l}\$ 680 \\
(15.8 \%)\end{array}$ & $\begin{array}{l}\$ 3640 \\
(11.5 \%)\end{array}$ & $\begin{array}{l}\$ 1900 \\
(10.4 \%)\end{array}$ & $\begin{array}{l}\$ 1750 \\
(11.0 \%)\end{array}$ & $\begin{array}{l}\$ 1420 \\
(12.1 \%)\end{array}$ & $\begin{array}{l}\$ 2180 \\
(11.2 \%)\end{array}$ \\
\hline $\begin{array}{l}\text { new retrofit ordi- } \\
\text { nance }\end{array}$ & $\begin{array}{l}-\$ 340 \\
(-10.4 \%)\end{array}$ & $\begin{array}{l}-\$ 280 \\
(-8.3 \%)\end{array}$ & $\begin{array}{l}-\$ 340 \\
(-7.7 \%)\end{array}$ & $\begin{array}{l}-\$ 410 \\
(-6.7 \%)\end{array}$ & $\begin{array}{l}-\$ 340 \\
(-8.0 \%)\end{array}$ & $\begin{array}{l}-\$ 2980 \\
(-9.4 \%)\end{array}$ & $\begin{array}{l}-\$ 1240 \\
(-6.8 \%)\end{array}$ & $\begin{array}{l}-\$ 1160 \\
(-7.3 \%)\end{array}$ & $\begin{array}{l}-\$ 970 \\
(-8.2 \%)\end{array}$ & $\begin{array}{l}-\$ 1590 \\
(-8.2 \%)\end{array}$ \\
\hline $\begin{array}{l}\text { no property in- } \\
\text { surance }\end{array}$ & $\begin{array}{l}\$ 280 \\
(8.2 \%)\end{array}$ & $\begin{array}{l}\$ 240 \\
(7.4 \%)\end{array}$ & $\begin{array}{l}\$ 320 \\
(7.2 \%)\end{array}$ & $\begin{array}{l}\$ 440 \\
(7.3 \%)\end{array}$ & $\begin{array}{l}\$ 320 \\
(7.5 \%)\end{array}$ & $\begin{array}{l}\$ 1200 \\
(3.8 \%)\end{array}$ & $\begin{array}{l}\$ 550 \\
(3.0 \%)\end{array}$ & $\begin{array}{l}\$ 500 \\
(3.2 \%)\end{array}$ & $\begin{array}{l}\$ 380 \\
(3.2 \%)\end{array}$ & $\begin{array}{l}\$ 660 \\
(3.4 \%)\end{array}$ \\
\hline $\begin{array}{l}40 \% \text { insured } \\
\text { properties }\end{array}$ & $\begin{array}{l}-\$ 570 \\
(-17.1 \%)\end{array}$ & $\begin{array}{l}-\$ 510 \\
(-15.3 \%)\end{array}$ & $\begin{array}{l}-\$ 670 \\
(-15.0 \%)\end{array}$ & $\begin{array}{l}-\$ 920 \\
(-15.2 \%)\end{array}$ & $\begin{array}{l}-\$ 670 \\
(-15.5 \%)\end{array}$ & $\begin{array}{l}-\$ 2470 \\
(-7.8 \%)\end{array}$ & $\begin{array}{l}-\$ 1140 \\
(-6.2 \%)\end{array}$ & $\begin{array}{l}-\$ 1030 \\
(-6.5 \%)\end{array}$ & $\begin{array}{l}-\$ 780 \\
(-6.6 \%)\end{array}$ & $\begin{array}{l}-\$ 1350 \\
(-7.0 \%)\end{array}$ \\
\hline $\begin{array}{l}\text { no unemploy- } \\
\text { ment insurance }\end{array}$ & $\begin{array}{l}\$ 0 \\
(0.0 \%)\end{array}$ & $\begin{array}{l}\$ 0 \\
(0.0 \%)\end{array}$ & $\begin{array}{l}\$ 0 \\
(0.0 \%)\end{array}$ & $\begin{array}{l}\$ 0 \\
(0.0 \%)\end{array}$ & $\begin{array}{l}\$ 0 \\
(0.0 \%)\end{array}$ & $\begin{array}{l}\$ 1760 \\
(5.6 \%)\end{array}$ & $\begin{array}{l}\$ 950 \\
(5.2 \%)\end{array}$ & $\begin{array}{l}\$ 600 \\
(3.8 \%)\end{array}$ & $\begin{array}{l}\$ 340 \\
(2.8 \%)\end{array}$ & $\begin{array}{l}\$ 910 \\
(4.7 \%)\end{array}$ \\
\hline $\begin{array}{l}\text { extended unem- } \\
\text { ployment insur- } \\
\text { ance }\end{array}$ & $\begin{array}{l}\$ 0 \\
(0.0 \%)\end{array}$ & $\begin{array}{l}\$ 0 \\
(0.0 \%)\end{array}$ & $\begin{array}{l}\$ 0 \\
(0.0 \%)\end{array}$ & $\begin{array}{l}\$ 0 \\
(0.0 \%)\end{array}$ & $\begin{array}{l}\$ 0 \\
(0.0 \%)\end{array}$ & $\begin{array}{l}-\$ 2080 \\
(-6.6 \%)\end{array}$ & $\begin{array}{l}-\$ 1170 \\
(-6.4 \%)\end{array}$ & $\begin{array}{l}-\$ 730 \\
(-4.6 \%)\end{array}$ & $\begin{array}{l}-\$ 410 \\
(-3.5 \%)\end{array}$ & $\begin{array}{l}-\$ 1100 \\
(-5.6 \%)\end{array}$ \\
\hline
\end{tabular}

\section{Effect of insurance availability for different income levels}

Due to the lack of data on geographical distribution of insurance penetration, the original analysis assumes spatially uniform distribution of earthquake insurance. However, wealthier people are more likely to purchase earthquake insurance because they have more assets at stake and are able to afford $i^{54}$. Therefore we investigate the effect that non-uniform insurance penetration would have on the overall asset and well-being losses. We consider three cases: geographically uniform insurance penetration, insurance penetration starting with the lowest income population, and insurance penetration starting with the highest income population. Results in Figure 10 show that increased insurance penetration among the highest income population would lead to the greatest decrease is non-insured asset losses. However, such a risk reduction strategy would be the least efficient in reducing well-being losses, where well-being losses could be reduced nearly twice as much if the poorest quartile is insured.
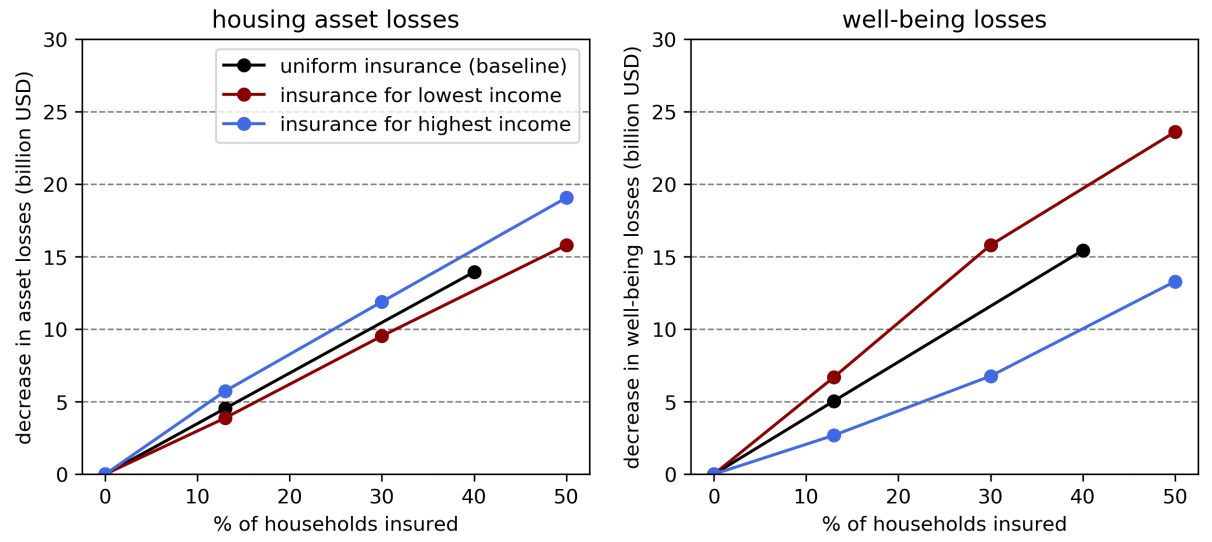

Figure 10. Decrease in total non-insured housing asset losses (left) and well-being losses (right) as a result of different levels of insurance penetration among population of varying incomes. 